\title{
The Role of Social Ties in Factor Allocation
}

\section{Ulrik Beck, Benedikte Bjerge, and Marcel Fafchamps}

\begin{abstract}
We investigate whether social structure helps or hinders factor allocation using unusually rich data from the Gambia. Evidence indicates that land available for cultivation is allocated unequally across households; and that factor transfers are more common between neighbors, co-ethnics, and kinship-related households. Does this lead to the conclusion that land inequality is due to flows of land between households being impeded by social divisions? To answer this question, a novel methodology that approaches exhaustive data on dyadic flows from an aggregate point of view is introduced. Land transfers lead to a more equal distribution of land and to more comparable factor ratios across households in general. But equalizing transfers of land are not more likely within ethnic or kinship groups. In conclusion, ethnic and kinship divisions do not hinder land and labor transfers in a way that contributes to aggregate factor inequality. Labor transfers do not equilibrate factor ratios across households. But it cannot be ruled out that they serve a beneficial role, for example, to deal with unanticipated health shocks.
\end{abstract}

JEL classification: C21, D85, OI2

Keywords: social networks, allocative efficiency, land markets, factor markets

Much attention has been devoted to identifying the sources of friction responsible for inefficient or inequitable economic outcomes. One particular area of investigation is the extent to which exchange is shaped by important aspects of social structure such as caste, ethnicity, kinship, and family ties. Examples of issues to which this approach has been applied include informal insurance (e.g., Townsend 1994; Fafchamps and Lund 2003; Fafchamps and Gubert 2007; Attanasio et al. 2012; Mazzocco and Saini 2012), labor markets (e.g., Granovetter 1995; Topa 2001), and international trade (e.g., Rauch 2001; Rauch and Casella 2003; Chaney 2014, among others).

While the literature has been successful at documenting important sources of friction, demonstrating that these frictions are responsible for aggregate misallocation has proved more difficult. The reason is that there typically exist many different ways of achieving an efficient or equitable outcome. The fact that

Ulrik Beck (corresponding author) is a senior economist at the Danish Economic Councils, Copenhagen, Denmark; his email address is urb@dors.dk. Benedikte Bjerge is an economic consultant; her email address is benediktebjerge@gmail.com. Marcel Fafchamps is a senior fellow at the Freeman Spogli Institute for International Studies, Stanford University, Stanford, CA; his email address is fafchamp@stanford.edu. We benefited from comments from seminar participants at the Universities of Oxford, UC-Berkeley, Paris 1, Gothenburg, and the Goethe University in Frankfurt, as well as conference participants at the CSAE conference 2014, the International Economic Association's World Congress 2014, and the Nordic Conference in Development Economics 2015. The authors also thank Dany Jaimovich, Thomas Markussen, Carol Newman, John Rand, Måns Söderbom, Finn Tarp, and three anonymous referees for their very valuable comments. Finally, we thank Jean-Louis Arcand and Dany Jaimovich for making the Gambia Networks Data 2009 available to us. A supplementary online appendix for this article can be found at The World Bank Economic Review website. 
social structure precludes or impedes some of these ways is not sufficient to demonstrate that it affects the final outcome.

To illustrate the problem, consider an exchange economy with $N$ economic agents, each endowed with a vector of goods. Achieving allocative efficiency requires goods to flow between agents. Let the flows between pairs of agents be represented as network links. The number of possible links between $N$ individuals is $N(N-1) / 2$, and the number of possible network configurations is $2^{N(N-1) / 2}$. For instance, if $N=10$, there are 45 possible links and more than 35 trillion network configurations. If one drops, say, 25 of these links because they are impeded by social structure, this still leaves 33 million possible network configurations-many of which can achieve efficiency, depending on the structure of the remaining network and the distribution of endowments. This shows that while friction can distort resource allocation, proving that it actually does is considerably more complicated. To demonstrate that misallocation arises because of a specific aspect of social structure, it is necessary to consider social links, pairwise flows, and aggregate allocation simultaneously. With a few exceptions (e.g., La Ferrara [2003] on credit and Sadoulet, de Janvry, and Fukui [1997]; Holden and Ghebru [2005]; and Macours, Janvry, and Sadoulet [2010] on land markets), ${ }^{1}$ this has seldom been done.

The purpose of this paper is twofold: to present a methodology that can identify whether resource misallocation is due to specific restrictions to flows between agents or groups of agents; and to illustrate its usefulness with an example that is relevant for development policy. The proposed method is potentially applicable to a wide range of questions. Its main use is to investigate whether a particular dimension of social structure may be involved in resource misallocation. It does so by checking that the pattern of flows across agents is consistent with the existence of frictions associated with a particular social structure. If no evidence is found, it implies that this particular aspect of social structure could not have caused the misallocation. ${ }^{2}$

The methodology is implemented by focusing on land allocation in village economies. Factor markets in developing countries are plagued by incomplete information and unclear property rights that lead to high transaction costs and are thought to hinder the allocation of productive factors (de Janvry, Fafchamps, and Sadoulet 1991; Pender and Fafchamps 2005; Otsuka 2007). Pre-existing social networks are thought to play an important role in alleviating these issues by increasing trust, decreasing information asymmetries, and reducing transaction costs. Such markets are thus a good test case for the methodology presented here.

Land ownership is notoriously unequal in many agrarian societies. At the same time, traditional agricultural systems are often characterized by decreasing returns to scale beyond a minimum scale of operations (see Ali and Deininger [2015] for an excellent recent review of the literature). A more efficient and equitable allocation of cultivated acreage thus requires temporary transfers of land from land-rich to land-poor farming households. It is also well known that homophily and discrimination are common in market and non-market exchange: many people prefer to trade and exchange favors with people who are socially proximate. The question therefore arises of whether homophily and discrimination contribute to the unequal allocation of cultivated acreage. Access to agricultural land is a sensitive political issue in

1 La Ferrara (2003) studies the role of kinship networks in credit in Ghana. She finds that two-thirds of the amounts borrowed come from potential kinsmen and that family structure helps enforce these loans, thereby improving the efficient allocation of funds within kin groups. Sadoulet, de Janvry, and Fukui (1997) compare land contracts between kin-related and non-kin-related households and find that the former are more efficient. Holden and Ghebru (2005) show that tenants in communities with a larger share of contracts between kin-related households face lower access constraints to the land market. More recently, Macours, de Janvry, and Sadoulet (2010) find that insecurity of property rights in the Dominican Republic reduces rental activity, and causes the tenancy market to match up along socio-economic lines. None of these authors use the general approach suggested here.

2 Unlike causal inference based on experimental evidence, the method presented in this paper does not aim to test one specific cause. Rather, it tests for the presence of a flow pattern that would have to be present for a particular type of social-structure-driven friction to cause resource misallocation. 
many developing countries because it is a major determinant of household welfare. Whenever access to land is impeded - or perceived to be impeded — by ethnic and other social divides, this can lead to violence, as has been seen in a number of developing countries. Identifying the dimensions of social structure that contribute to unequal access to land can thus make a valuable contribution to conflict prevention.

The empirical analysis takes advantage of an unusually rich dataset on land and labor transactions in rural Gambia. Land usage rights in rural Gambia are vested in the hands of the descendants of the ancestral settlers, and thus the distribution of land ownership rights is highly unequal. This results in an abundant practice of land exchange between households whereby temporary land usage rights are transferred on an annual basis. This makes the Gambia a suitable candidate for testing how pre-existing networks in the form of ethnicity, kinship, and geographical proximity affect the efficiency properties of temporary land transfers. The data cover all pairwise transfers of agricultural land and labor in 50 rural Gambian villages, together with information on pre-existing social links between each pair of households. The focus is exclusively on the factor transfers themselves, not on the form (e.g., gift, rental, sharecropping) or motivation (e.g., reciprocity, self-interest) of the transactions-these are examined in detail, for the dataset at hand, by Jaimovich (2011), Jaimovich (2015), and Beck and Bjerge (2017). The methodology of this paper is based on flows only, and the main results of the paper do not depend on the underlying mechanism behind these flows.

Land ownership and cultivated acreage are unequally distributed across farmers, with systematic differences between ethnic groups. Further, transfers of temporary usage rights over land are more common between neighbors or family-related households. Prima facie evidence thus suggests the presence of frictions between non-neighbors and unrelated households. But do these frictions contribute to aggregate inequality in cultivated acreage?

There is no evidence that ethnic or kinship groupings distort land transfers away from an equal distribution of land. In other words, the data reject the idea that preferential exchange between certain farmers contributes to land inequality. The main reason seems to be that a small number of land-rich households transfer land to non-co-ethnic farmers in their village, and these transfers are sufficient to compensate for the abundance of small land transfers between socially proximate households. These findings are in agreement with the anthropological and historical literature about land settlement in sub-Saharan Africa, which emphasizes the redistributive role of pioneer lineages who control the village land that their ancestors cleared, but who welcome newcomers into their community with transfers of usage rights over land (Platteau 1992).

The paper contributes to the literature in several different ways. The first contribution is methodological. There can be many ways by which goods can end up in the right hands by traveling along pre-existing social ties. The proposed method empirically resolves this difficulty by approaching exhaustive data on dyadic flows from an aggregate point of view. This method is applicable well beyond factor markets in developing countries. It is potentially applicable to research questions as diverse as gravity models and international trade; labor markets; value chains; favor exchange; electrical power grids; and diffusion of information on social networks. As argued in more detail in the supplementary online appendix, all these questions have in common that flows take place on a network of links that are partially shaped by the geographical and social context. The same question arises in all of them: Do restrictions on flows potentially imposed by social structure lead to an inefficient or inequitable allocation of resources, as evidenced by unequal marginal productivities or utilities-or ratios thereof? The main constraint to the applicability of the method is the availability of exhaustive information about dyadic flows, and sufficiently detailed information about social structure. While such datasets have largely been lacking in the past, they are becoming increasingly available. The methodology can also be applied to study whether differences in prices, costs, access, or opportunities are due to social, geographical, or regulatory obstacles to exchange. The empirical application presented in this paper illustrates how the method can be used to identify situations in which social structure is an obstacle to an efficient or equitable resource allocation. 
Second, the paper contributes to the empirical literature on the importance of pre-existing social networks for offsetting the negative effects of market imperfections. There is some evidence to this effect-but perhaps not as much as anticipated, based on the existing literature. Third, this paper provides empirical evidence on the efficiency properties of social networks in the Gambia, a country that is fairly representative of West African rural institutions. If pre-existing social networks are important for the selection of trading partners, this has direct implications for the prospects of reducing poverty and inequality as well as economic growth (Holden, Otsuka, and Place 2009). This issue is particularly important in West Africa, where access to land is an increasing concern as land scarcity increases due to population growth (African Development Bank 2005). Land ownership is unequally distributed within villages of the Gambia, with some systematic advantage to members of the majority ethnic group in each village. Land transfers serve a modest but significant role in equalizing factor allocations between households, and they do so in a way that appears unimpeded by ethnic and kinship divisions. Geographical proximity, in contrast, appears to have a factor-equalizing effect over and above that of village-level equalization.

The paper is organized as follows. Section 1 lays out the conceptual framework of the analysis. Section 2 presents the methodology and articulates a novel testing strategy aimed at identifying the role of social ties in shaping transfers. The section starts by showing how the method works for a single good. It is then illustrated how it can be applied to study allocative efficiency in factors of production. The rest of the paper applies this method to agrarian factor markets in the Gambia. Section 3 describes the land tenure system in rural Gambia and the data used in the empirical analysis. In section 4, the testing strategy is applied to the data and main results of the empirical analysis are presented. Section 5 discusses alternative interpretations of the empirical findings and provides a number of robustness checks. Section 6 concludes.

\section{Conceptual Framework}

In this paper, a method for testing whether misallocation of resources can be ascribed to frictions to the flow of goods that are associated with a particular aspect of social structure is proposed and tested. Much attention has been devoted to testing whether goods or services flow less freely between certain economic agents than others. Studies using data at the plant level have documented how misallocations of input factors contribute to differences in total factor productivity across countries (Alfaro, Charlton, and Kanczuk 2008; Hsieh and Klenow 2009; Midrigan and Xu 2014). Frictions have also been documented between individuals. In a meta analysis of controlled experiments in 10 countries, Riach and Rich (2002) note that "significant, persistent and pervasive levels of discrimination have been found against non-whites and women in labour, housing and product markets." Experimental evidence of labor market discrimination is also reported by Bertrand and Mullainathan (2004), Goldin and Rouse (2000), and Carlsson and Rooth (2007), among others. In the same vein, Edelman, Luca, and Svirsky (2017) find that white landlords of a well-known online platform are less likely to rent to black tenants. Hanson and Hawley (2011) report similar evidence in the housing market. Fafchamps and Gubert (2007) find that risk-sharing transfers occur primarily between neighbors and relatives.

While this body of work provides compelling evidence of frictions, it does not by itself imply that discrimination causes misallocation: Individuals who are discriminated against by some employers or landlords may find equivalent employment elsewhere. Whether frictions cause misallocation depends on whether they impede flows sufficiently for misallocation to arise.

An intuitive way of visualizing the issue is from a high school physics example, namely, communicating vessels. ${ }^{3}$ Imagine a set of $N$ vessels linked to each other by pipes. Unequal amounts of water are poured into these vessels, with $a_{i}$ denoting the water poured into vessel $i$. Think of vessels as representing households and water as being any good or service that is exchanged between them, either through market or 
non-market exchange. Water pipes represent the social structure. Equalization of water levels represents the equalization of marginal productivities or utilities_or of their ratios (see the supplementary online appendix for examples).

Physics theory informs us that water levels will be equalized among all communicating vessels. This can be represented formally as a network or graph in which each vessel is a node and each pipe is a link $L_{i j}$ between two nodes $i$ and $j$. Friction across social groups usually translates into clustering within groups-that is, more links between group members. Yet, if all vessels are connected either directly or indirectly, they all belong to the same component and water levels will equalize across all of them. In other words, clustering/preferential attachment does not impede equalization. Alternatively, the network may be divided into multiple components, that is, into distinct subsets of nodes that are connected with other nodes in the same component, but not with any node in other components. In that case, water levels will equalize within components but not across components.

What this example shows is that equalization of levels cannot be predicted by clustering: Links (and hence flows) may be more frequent within certain subsets of the network, for example, between co-ethnic nodes; but all nodes within the same component have equal access to water. It is only when social structure precludes flows between components that access can be unequal. Even in this case, however, water level equalization can occur if the water endowment of each component is proportional to their number of nodes. It follows that level equalization depends both on the distribution of initial endowments and on aggregate properties of the network-in this simple case, its partition into distinct components. Local network properties like clustering/preferential attachment have little predictive power. Similar conclusions apply to other distributive networks.

This example can be amended to allow only some of the water to go through individual pipes. ${ }^{4}$ Let $s_{i j} \geq 0$ be the maximum amount of water that can flow from $i$ to $j$, and let $S \equiv\left[s_{i j}\right]$ denote the matrix of all $s_{i j}$. If there is no pipe between $i$ and $j, s_{i j}=0$. When flows are constrained, it is difficult to determine a priori whether equalization can be achieved within components or even between any pair of nodes $i$ and $j$. In particular, it is not possible to predict whether equalization will be achieved between any pair of nodes $i$ and $j$ simply from knowing their local properties $s_{i j}, a_{i}$, and $a_{j}$. Even if $i$ and $j$ are not connected $\left(s_{i j}=0\right)$, water may flow between them through other nodes, equalizing water levels between them. In contrast, even when the connection between the two nodes is sufficient to equally share their initial endowments $a_{i}$ and $a_{j}$, flows to and from other nodes may prevent pairwise equalization between them. ${ }^{5}$ Hence it is not because flows are restricted between $i$ and $j$ that equalization cannot be achieved, and it is not because flows between $i$ and $j$ are less constrained that equalization will be achieved between them. The same reasoning applies to other distributed networks, for example, electric power grids, value chains, gravity models, and the like. ${ }^{6}$

Several lessons can be drawn from the above discussion. First, observing that individual flows are shaped by local social structure does not imply that allocation is unequal. The reverse is also true: The fact that social structure does not shape flows does not imply equal access-there can be obstacles to flows that are not correlated with social structure. Finally, observing that social structure shapes individual flows

4 To take another example, an electrical power grid may be interconnected, but the flow of power between different points is often restricted by technological constraints. If one segment of the grid fails, it may not be possible to channel enough current from the rest of the grid to avoid a loss of service, resulting in a power outage.

5 To illustrate, consider a network with three nodes $\{1,2,3\}$ arranged in a line, with $s_{12}=1$ and $s_{23}=1$. Endowments are $\{0,2,2\}$. Consider nodes 1 and 2 first. Water equalization implies a transfer of 1 from node 2 to node 1 , which is feasible since $s_{12}=1$. Suppose this takes place. Node 1 now has 1 unit of water, and so does node 2 . Now consider nodes 2 and 3: Equalization between them leads to a transfer of 0.5 units of water from node 3 to node 2, which now has 1.5 units of water. Since 1 unit of water has already been transferred from 2 to 1 , further water equalization between them is impossible, and the final allocation is $\{1,1.5,1.5\}$ : There is no water level equalization between 1 and 2 even though $s_{12}$ is large enough to equalize their respective endowments.

6 Bramoullé and Kranton (2007) provide other examples in risk sharing games on networks. 
and that allocation is unequal does not, by itself, imply that one causes the other. To address the latter issue, a methodology that identifies situations in which the pre-existing social structure is responsible for unequal allocation is proposed.

\section{Testing Strategy}

Given that the method is applied to land and labor transfers later in the paper, the testing strategy is framed in terms of factors of production. But it is in principle applicable to any good or service, and to any flows-whether they take place in a centralized manner, or through decentralized market or nonmarket exchange.

Consider an economy with $N$ farming households observed during a single cropping season. Each household starts the season with $a_{i}$ units of a single factor of production, say, land. The total supply of $a$ in the economy is denoted $A \equiv \sum_{i=1}^{N} a_{i}$. Each agent shares the same production function $q\left(x_{i}\right)$, where $x_{i}$ denotes the land available for cultivation by agent $i$. It is assumed that $q\left(x_{i}\right)$ exhibits decreasing returns to scale in $x_{i}{ }^{7}$ The efficient factor allocation is to set $x_{i}=\bar{a}=\frac{A}{N}$ to equalize the allocation of land across households. In the absence of frictions, this allocation can be expected to be realized through mutually beneficial exchange. ${ }^{8}$ Given these assumptions, failure to equalize land across households signals the presence of frictions. The object of interest is to what extent the failure to achieve an efficient allocation is associated with specific aspects of observable social structure.

Let $l_{i}$ be the net amount of $a$ that is transferred out by household $i$. Allocative efficiency requires that households have equal amounts of land after transfers, that is, that $a_{i}-l_{i}=\bar{a}$, which implies that $l_{i}=a_{i}-\bar{a}$ for all $i$. A regression of the following form can be employed to investigate whether the average factor transfer is efficiency enhancing:

$$
l_{i}=\alpha_{0}+\alpha_{1}\left(a_{i}-\bar{a}\right)+u_{i} .
$$

Allocative efficiency requires $\alpha_{1}=1$. Land transfers are efficiency enhancing if $0<\alpha<1$. This occurs when, on average, land-rich households transfer land out and land-poor households receive land transfers.

While easily implementable, regression (1) does not allow testing the effect of pre-existing networks on the efficiency properties of factor transfers. To do so, the analysis is moved to the dyadic level, that is, the pairwise level. Factor transfers between households can be represented by a weighted directed graph in which agents are nodes and transfers are links. Let $w_{i j}$ denote a net transfer of $a$ from agent $i$ to agent $j$ with $w_{j i}=-w_{i j}$ by definition. Let the transfer matrix $W \equiv\left[w_{i j}\right]$ denote the set of all pairwise transfers. Simple accounting implies that transfers satisfy:

$$
\begin{aligned}
x_{i} & =a_{i}-\sum_{j \neq i} w_{i j} \\
\sum_{i} x_{i} & =A
\end{aligned}
$$

subject to feasibility conditions of the form:

$$
x_{i} \geq 0 \text { for all } i .
$$

Let $W^{*}$ denote a transfer matrix that satisfies the feasibility conditions and achieves efficiency, that is, such that $x_{i}=\bar{a}$ for all $i$. Call such matrices efficient. There is a very large number of efficient matrices

7 This assumption is discussed in more detail later.

8 The reallocation of land among households can be organized in a variety of market (e.g., sale, rental, or sharecropping) and non-market ways (gift exchange, exchange of usage rights, or squatting). Since the focus is on allocative efficiency, only the transfers themselves are considered in this paper, not the mechanisms by which land is transferred and the gains from trade shared between households. 
$W^{*}$, which means that the specific factor transfers that are needed to achieve efficiency are undetermined. The reason is simple. Say that a necessary condition for efficiency is that $i$ transfers 3 units of land to others. This can be achieved in myriad ways, for example, by giving 1 to $j$ and 2 to $k$, or 1.5 to $j$ and 1.5 to $k$, or 3 to $m$, and so forth.

\section{Testing Aggregate Allocative Efficiency}

While it is not possible to determine which specific trades take place without introducing additional assumptions, ${ }^{9}$ it is possible to provide some characterization of average trade flows if they serve to improve allocative efficiency within a village $v$ with average landholdings $\bar{a}_{v}$ and population $N_{v}$.

The logic is best illustrated with an example. Starting from an unequal factor distribution in village $v$, allocative efficiency requires that those with an above-average endowment transfer out $a_{i}-\bar{a}_{v}$ and that those with a below-average endowment receive in $\bar{a}_{v}-a_{i} \cdot{ }^{10}$ Although there are many transfers $w_{i j}$ that can achieve this result, allocative efficiency requires that for each $i$, the sum of $i$ 's out-transfers satisfies $\sum_{j} w_{i j}=a_{i}-\bar{a}_{v}$. Similarly, the sum of in-transfers is $\sum_{j} w_{i j}=\bar{a}_{v}-a_{j}$. Thus, if all net transfers $w_{i j}$ in village $v$ are observed, a regression of the following form can be estimated:

$$
w_{i j}=\alpha_{0}+\alpha_{1} \frac{a_{i}-\bar{a}}{N_{v}}+\alpha_{2} \frac{\bar{a}-a_{j}}{N_{v}}+u_{i j}
$$

over all $N_{v}\left(N_{v}-1\right)$ dyads. Since $w_{i j}=-w_{j i}$ by construction, it follows that $\alpha_{0}=0$ and $\alpha_{1}=\alpha_{2}$ always.

If land transfers achieve an efficient allocation, it must be that $\alpha_{1}=1=\alpha_{2}$. Simulation results detailed in the supplementary online appendix confirm this property. The supplementary online appendix also shows that $\alpha_{1}$ provides an estimate of how far actual transfers are from efficient transfers: For any set of efficient transfers $w_{i j}^{*}$ that are multiplied by a shrinking factor $\tau<1$ such that $w_{i j}=\tau w_{i j}^{*}$, then $\alpha_{1}=\tau=\alpha_{2}$. Hence, the closer $\alpha_{1}$ is to zero, the less efficiency gains are achieved by land transfers.

\section{Testing Group-wise Efficiency}

Now suppose that transfers can only take place between certain pairs of nodes-for example, because social ties are needed to mitigate information asymmetries and enforcement problems. To fix ideas, let $S \equiv\left[s_{i j}\right]$ denote, as before, the set of maximum socially feasible flows such that:

$$
\left|w_{i j}\right| \leq s_{i j} \text { for all } i j \text {. }
$$

$S$ is not observed directly. Instead, pre-existing social links thought to reduce frictions are used as proxy variables for $s_{i j}$ : If the absence of a particular type of social link between $i$ and $j$ precludes factor transfers, then one can expect $w_{i j}=s_{i j}=0$.

Can efficiency be achieved? This depends on whether there exists an efficient transfer matrix $W^{*}$ that satisfies the set of constraints (3). If such a matrix exists, allocative efficiency can be achieved even though transfers can only occur along existing social ties. If it does not, restrictions imposed by matrix $S$ prevent allocative efficiency from being reached-unless aggregate land endowments happen to be identical across groups.

As discussed earlier, allocative efficiency may be prevented when the network is segmented into distinct components. Formally, this means that the set of nodes $N$ can be partitioned into mutually exclusive sets $\left\{N_{1}, \ldots N_{p}\right\}$ such that (1) there is a path in $S$ leading from any node in $N_{k}$ to any other node in $N_{k}$; and (2) there is no path in $S$ leading from a node in $N_{k}$ to a node in $N_{m \neq k}$. In this case, allocative efficiency

9 For example, one could ask which transfer matrix $W$ minimizes the number of separate transfers needed to achieve efficiency. Since it is unclear how these trades could be implemented in a decentralized manner, it is not discussed further.

10 Let $N_{1}$ and $N_{2}$ denote the number of agents with an above- and below-average endowment, that is, with $a_{i}-\bar{a}_{v}>0$ and $a_{j}-\bar{a}_{v}<0$, respectively. The $N-N_{1}-N_{2}$ others have an allocatively efficient endowment such that $a_{k}=\bar{a}_{v}$. Allocative efficiency requires that $N_{1}$ agents collectively transfer out $\sum_{i \in N_{1}} a_{i}-\bar{a}_{v}$ and $N_{2}$ agents collectively transfer in $\sum_{j \in N_{2}} \bar{a}_{v}-a_{j}$. 
is only possible within each component. It follows that if average factor endowments are identical across components, allocative efficiency can be achieved since it does not require flows across components. If average endowments vary across components, however, allocative efficiency is precluded since it requires flows between components.

In this case, applying model (2) separately to each component yields:

$$
w_{i j}=\alpha_{0}+\alpha_{3} \frac{a_{i}-\bar{a}_{k}}{N_{k}} D_{i j}+\alpha_{4} \frac{\bar{a}_{k}-a_{j}}{N_{k}} D_{j i}+u_{i j},
$$

where $N_{k}$ is the size of the component $k, \bar{a}_{k} \equiv \frac{1}{N_{k}} \sum_{i \in N_{k}} a_{i}$ is the average endowment in component $k$, and $D_{i j}=1$ if $i$ and $j$ belong to the same component $k$ and 0 otherwise. As before, $\alpha_{0}=0$ and $\alpha_{3}=\alpha_{4}$ always. Allocative efficiency within components requires $\alpha_{3}=1=\alpha_{4}$, and the magnitude of $\alpha_{3}$ captures the extent to which transfers achieve within-component equalization of land available for cultivation. See the supplementary online appendix for illustrative examples.

An extreme case of this is when transfers are only possible across pairs of agents-for example, between neighbors or between brothers. In this case, the regression model simplifies to:

$$
w_{i j}=\alpha_{0}+\alpha_{5} \frac{a_{i}-a_{j}}{2} L_{i j}+u_{i j}
$$

where $L_{i j}=1$ if there is a direct link between $i$ and $j$ in $S$, and 0 otherwise. If allocative efficiency is only achieved across isolated linked pairs of agents, then $\alpha_{0}=0$ and $\alpha_{5}=1$. An illustration is provided in the supplementary online appendix.

\section{Testing Social Structure}

To investigate the role of social structure in allocative efficiency, we combine the estimation of individual models (2), (4), and (5) with various joint models discussed below. As long as average factor endowments differ between social groups, the same method applies. From model (2), an estimate $\widehat{\alpha}_{1}$ of how far transfers are from being allocatively efficient on average is obtained; if $\widehat{\alpha}_{1}<0$, it means that transfers move land allocation away from efficiency. Comparing $\widehat{\alpha}_{1}$ to $\widehat{\alpha}_{3}$ in model (4) shows whether more efficiency is achieved within components than in aggregate. If $\widehat{\alpha}_{3}>\widehat{\alpha}_{1}$, this indicates that the lack of social links between components hinders aggregate efficiency. Similarly, if $\widehat{\alpha}_{5}>\widehat{\alpha}_{1}$, more efficiency gain is achieved within pairs than in aggregate. In all these cases, identification requires average factor endowments to differ across social groupings. Indeed, when average endowments are identical across groupings, no flow is required for efficiency and thus restrictions on flows have no identifiable effect on aggregate efficiency.

Results can be further refined by estimating joint models of the form:

$$
\begin{aligned}
w_{i j}= & \alpha_{0}+\alpha_{1} \frac{a_{i}-\bar{a}_{v}}{N_{v}}+\alpha_{2} \frac{\bar{a}_{v}-a_{j}}{N_{v}} \\
& +\alpha_{3} \frac{a_{i}-\bar{a}_{k}}{N_{k}} D_{i j}+\alpha_{4} \frac{\bar{a}_{k}-a_{j}}{N_{k}} D_{i j}+u_{i j} \\
w_{i j}= & \alpha_{0}+\alpha_{1} \frac{a_{i}-\bar{a}_{v}}{N_{v}}+\alpha_{2} \frac{\bar{a}_{v}-a_{j}}{N_{v}}+\alpha_{5} \frac{a_{i}-a_{j}}{2} L_{i j}+u_{i j} .
\end{aligned}
$$

In model (6), two types of differences can arise between $\frac{a_{i}-\bar{a}_{v}}{N_{v}}$ and $\frac{\bar{a}_{v}-a_{j}}{N_{v}}$ on the one hand, and $\frac{a_{i}-\bar{a}_{k}}{N_{k}} D_{i j}$ and $\frac{\bar{a}_{k}-a_{i}}{N_{k}} D_{i j}$ on the other: $\bar{a}_{v} \neq \bar{a}_{k}$; and $D_{i j}=0$ for some pairs. If average endowments differ across components, convergence toward the village average can take the allocation of land away from allocative efficiency within components. This results in $\widehat{\alpha}_{3}=\widehat{\alpha}_{4}<0$ while at the same time the estimates of $\alpha_{1}$ and $\alpha_{2}$ in (6) are larger than in (2). In contrast, if transfers serve to equalize land within components more than across components, then $\widehat{\alpha}_{3}=\widehat{\alpha}_{4}>0$ and $\widehat{\alpha}_{1}$ and $\widehat{\alpha}_{2}$ tend to zero. 
A similar reasoning applies to (7): If improvements in allocative efficiency are achieved solely through transfers across linked pairs, $\widehat{\alpha}_{1}$ and $\widehat{\alpha}_{2}$ tend to zero while $\widehat{\alpha}_{5}$ remains positive. In contrast, if individual pairwise links place no restrictions on aggregate efficiency gains, that means that $\widehat{\alpha}_{5}$ tends to zero while $\widehat{\alpha}_{1}=\widehat{\alpha}_{2}>0$.

\section{Extensions}

To explain the testing strategy, the focus has been on a simple case in which returns to scale are decreasing and there is a single traded factor. The advantage is that this case closely resembles the communicating vessels example: Allocative efficiency requires land equalization, and the role of social structure can be investigated by testing whether transfers equalize land available for cultivation across all households, within components, or across individually linked pairs. Before taking this testing strategy to the data, however, a natural question to ask is whether assuming decreasing returns to scale and a single traded factor makes sense for the context of the current study. While the data at hand do not contain specific information about yields, it is well known that in the kind of traditional farming area under study, yields fall with farm size. This has been well documented in the literature (e.g., Ali and Deininger 2015). ${ }^{11}$ Hence, it is not unreasonable to assume that returns to farm size are decreasing for the purpose of this study. As documented in the next section, trade in labor is much less prevalent than land transfers, suggesting that at least as a first approximation, assuming a single traded factor is not entirely unreasonable either.

What cannot be ruled out is that farmers differ in terms of productivity-for example, because of differences in agricultural knowledge, business acumen, or household labor mobilization. So far, a maintained assumption has been that all households share the same decreasing returns to scale production function $q\left(x_{i}\right)$. In this case, allocative efficiency requires equalization of land across all farms. If households differ in productivity, however, land equalization is no longer efficient. The method can nonetheless be applied if productivity differences across farmers are multiplicative (i.e., Hicks-neutral). In this case, allocative efficiency requires equalization of factor ratios. In the supplementary online appendix, it is shown how models (2), (4), (5), (6), and (7) can be modified for this case by replacing the land endowment $a_{i}$ with factor ratios throughout. ${ }^{12}$

\section{Data}

To illustrate the testing strategy outlined in the previous section, a unique dataset, the Gambia Networks Data 2009, is used, which was collected in six out of eight local government areas between February and May 2009. A sample of 60 villages was randomly selected among villages with between 300 and 1,000 inhabitants in the 2003 census. Restricting the sample to small villages is motivated by the desire to obtain complete dyadic data on factor transfers for each entire village. Collecting similar data in larger villages would have been impractical. For more detailed information on the data collection strategy, see Jaimovich (2015). The sample is representative of smaller villages of the Gambia, which account for 20 percent of villages in the country (Arcand and Jaimovich 2014). Data were collected on each household in each village using a structured group interview approach. Information is available on the land $a_{i}$ and labor $l_{i}$ endowments of each household, as well as on all land and labor transactions $w_{i j}$ within each village for an entire agricultural year. The data also contain information on pre-existing social links.

11 The few cases of increasing returns to farm size that have been documented in the literature seem to coincide with large differences in technological know-how between farmers, and may in fact signal high returns to human capital combined with the presence of readily available technological innovations. See also Allen and Lueck (1998) and Deininger and Feder (2001). For the Gambia, see Kargbo (1983) and von Braun and Webb (1989).

12 The supplementary online appendix also contains an in-depth discussion of other possible models and their predictions regarding efficiency-enhancing reallocation of factors. 
Six villages are dropped from the analysis presented here because of missing household-level information. Given that the empirical focus is on factor transfers in agriculture, three semi-urban villages are dropped ${ }^{13}$ and the analysis is restricted to households whose main activity is farming. ${ }^{14}$ The sample used for the empirical analysis consists of 1,625 households across 50 villages, corresponding to 54,144 within-village dyads. Descriptive statistics paint a picture typical of rural Gambia. ${ }^{15}$

Rural villages in the Gambia are organized around compounds. A compound is a group of buildings, used for housing, storage, and other purposes, that are located in relative proximity to each other, typically around a central courtyard. Most often, a compound has a single household head that makes decisions regarding production and other daily activities. Sometimes a compound has several decision-makers. In such cases, independent production units (dabadas) can exist within the compound and independent consumption and cooking units (sinkiros) can exist within a single compound or within a single dabada (von Braun and Webb 1989; Webb 1989). Since the interest is in production decisions, the dabada is used as the unit of observation. If several dabadas reside within the same compound, the data contain information about the social links between them. Fourteen percent of household heads in the sample are not heads of the compound in which they live.

\section{Endowments and Transfers of Land and Labor}

In the Gambia, all land is nominally owned by the state, but usage rights are determined by the indigenous land tenure system (Freudenberger 2000). Two principal types of usage rights exist, which are referred to as primary and secondary. A household with primary rights over a plot of land can not only decide which crops to grow but also whether to lend all or some of the land to another farmer-in which case this farmer gains secondary rights over that land. A household with secondary rights over a plot has full control over its agricultural management while they maintain secondary rights over it.

Landless and land-poor households can obtain secondary usage rights to land in two ways (Freudenberger 2000). First, households with surplus land have a moral obligation to transfer secondary rights over some of it to those in need. The village chief, in particular, often has a land reserve from which he can allocate land to households in need. Second, usage rights over land can be accessed through market-based transactions such as land rental. Sharecropping is not a common practice in the Gambia. ${ }^{16}$ The questionnaire was designed to capture both monetary and non-monetary transfers of secondary usage rights. In practice, most transfers are non-monetary, although small payments in cash, kola nuts, or labor services sometimes are made to mark the fact that the secondary user continues to recognize the primary rights of the owner over the land (Eastman 1990; Freudenberger 2000; Jaimovich 2011). This practice is common in African land tenure systems (e.g., Platteau 1992) and is confirmed by field observations made during the survey.

Secondary usage rights are temporary in nature. Plots are borrowed on an annual or seasonal basis (Chavas, Petrie, and Roth 2005). This means that households with few or no primary usage rights to land must secure or renew secondary usage rights every year. The overwhelming majority of land transfers recorded in the survey relate to annual or seasonal usage rights.

Eighty-two percent of farming households have some primary usage rights to land, and their average land, holding is 10.5 hectares per household (see table 1 ). The distribution of primary usage rights is highly

13 In terms of network activity, 2 percent of the households in the semi-urban villages participate in the land market, while 10 percent participate in the labor market. The main reason for the absence of land sharing is probably the very small landholdings in these areas ( 0.24 hectares per household compared to 10.28 in the rural villages), and the much higher availability of employment opportunities outside the village.

14 Village-level averages such as $\bar{a}$ and $\bar{r}$ are calculated for farmers only.

15 See supplementary online appendix S2 for additional discussion and descriptive statistics.

16 Dey (1982) describes how donor-supported sharecropping schemes in the Gambia were unsuccessful and quickly abandoned. 
Table 1. Descriptive Statistics on Land and Labor

\begin{tabular}{lcc}
\hline & Mean & Std. Dev. \\
\hline Have primary usage rights to land & $81.9 \%$ & \\
Land owned with official rights (hectares) & 10.5 & 24.5 \\
Gini coefficient of land owned & 0.52 & \\
Ratio of land share to population share of main ethnic group & 1.2 & 7.39 \\
Land-labor ratio (hectares land per active worker) & 2.76 & 2.83 \\
Participates in land transfers & $45.2 \%$ & 0.307 \\
Land transfer (hectares) & 1.04 & 10.4 \\
Land transfer (\% of donors' land endowment)* & $37.6 \%$ & 15.4 \\
Number of working adults & 5.4 & $54.4 \%$ \\
Participates in labor transfers (within the village) & 5.3 & \\
Labor transfer (days) & & \\
\hline
\end{tabular}

Source: Author's own calculations on the Gambia Networks Data 2009.

Note *Conditional on transferring out land. Excludes observations where the donor is also a receiver.

unequal, however, with some households having less than 0.5 hectares and others more than 100 hectares. The Gini coefficient of primary land rights, averaged over the 50 villages, is 0.52 , and the share of land in the hands of the 10 percent most land-rich households is 34 percent on average. This unequal distribution is partly a result of the process of village settlement-which, in the case of much of sub-Saharan Africa, tends to be relatively recent. ${ }^{17}$ According to African customs, village founders acquire primary usage rights over the land they clear. Upon their death, these rights are passed on to their descendants. As the village grows by attracting new members from other lineages and ethnic groups, descendants of the village founders tend to retain rights over more of the village land.

The unequal ownership of land is reflected in the social structure: Members of the founder lineages have intermarried and tend to belong to the same ethnic group. Therefore, owners of much of the land tend to come from the same ethnic group and to all be related to each other: A village's main ethnic group typically owns more land than its share of the population—the ratio between the two exceeds 1 on average (see table 1). Similarly, households in the village's largest kinship group on average own more than three times more land than households outside that group. There is therefore much scope for increasing allocative efficiency by transferring secondary land usage rights from descendants of the village founders to relative newcomers. Efficiency-enhancing transfers of land should thus flow primarily from founder lineages to other ethnic and kinship groups. It is nonetheless unclear whether moral obligations to transfer usage rights to land-poor households are sufficiently strong to extend across ethnic and kinship lines.

The dataset also contains information about labor endowments. Households have an average of 5.4 working-age adults. The corresponding land-labor ratio is 2.8 hectares per working adult on average among the farming households in the sample. While this indicates that land is relatively abundant on average, land endowments are inequitably distributed, so that the median land-labor ratio is 1 hectare per working adult.

These observations form the main motivation for the empirical investigation: The settlement history of Gambian villages has generated a highly unequal distribution of primary land rights that partly coincides with ethnic and kinship divides. Hence the main research question of this paper: Are transfers of secondary land rights hindered by social structure, thereby hindering allocative efficiency?

17 It is estimated that a hundred years ago, Africa had less than 100 million inhabitants, possibly as few as 50 million. This compares to the current population of approximately 1 billion. The offshoot of this reality is that the majority of African villages in existence today were probably created in the last century (see Arcand and Jaimovich [2014] for more detail on the case of the Gambia). 
Descriptive statistics on participation in land and labor transfers, in the sample as a whole, and separately by land-labor ratios are provided in table 2 . Around 45 percent of households engage in land transfers, and households that export land typically transfer land to more than one household. Land transfers amount to 38 percent of the initial land endowments of the land-exporting households. At the receiving end, 36 percent of landless households in the sample receive secondary land rights from other households. ${ }^{18}$

A large proportion of households participate in labor transfers (54 percent). But the average household head only spends 5.4 days working on someone else's farm. This is small compared to land transfers, which amount to more than one hectare of land per household, or around 10 percent of their average land endowment. One possible interpretation, often proposed in the literature (e.g., Ali and Deininger 2015), is that transaction costs are higher for labor than land transfers-possibly because of supervision difficulties. ${ }^{19}$ For this reason, labor markets in subsistence agriculture are very thin throughout most of West Africa (Otsuka 2007; Holden, Otsuka, and Place 2009). ${ }^{20}$ Since land transfers by definition take place before labor transfers, transfers of secondary land rights serve to reduce differences in land-labor ratios across households ex ante, so as to obviate the need for ex post adjustment through labor transactions. As a result, the primary role of labor transactions is to deal with shocks in household manpower availability, for example, through illness.

A cursory look at the data reveals that as anticipated, households with a higher initial land-labor ratio are more likely to transfer out land and less likely to transfer in land. The same pattern is not evident for labor: Land-abundant households are not more likely to transfer in labor, suggesting that labor transfers do not serve to equalize land-labor ratios across households. For these reasons, the empirical analysis is largely focused on transfers of secondary land rights.

Table 2. Land and Labor Market Participation Rates by Initial Land-Labor Ratios

\begin{tabular}{lcccccc}
\hline & All & Landless & $0.1-0.6 \mathrm{ha} / \mathrm{w}$ & $\mathbf{0 . 6}-\mathbf{1 . 6} \mathrm{ha} / \mathrm{w}$ & $\mathbf{1 . 6 - 3 . 0 ~ h a / w}$ & $3.0 \mathrm{ha} / \mathrm{w}$ \\
\hline Land transfers: & & & & & & \\
Participates (\%) & 45.2 & 36.1 & 42.4 & 41.1 & 53.8 & 56.5 \\
Land sender (\%) & 21.0 & 2.0 & 14.9 & 19.0 & 30.1 & 40.5 \\
Land receiver (\%) & 28.9 & 35.7 & 33.3 & 26.2 & 30.5 & 21.4 \\
Labor transfers: & & & & & & \\
Participates (\%) & 54.4 & 42.5 & 49.8 & 56.6 & 64.3 & 57.5 \\
Labor sender (\%) & 36.9 & 30.6 & 34.1 & 39.5 & 43.6 & 34.7 \\
Labor receiver (\%) & 32.3 & 23.8 & 27.5 & 30.6 & 41.0 & 39.8 \\
Observations & 1,625 & 294 & 255 & 516 & 266 & 294 \\
\hline
\end{tabular}

Source: Author's own calculations on the Gambia Networks Data 2009.

Note: ha/w corresponds to the number of hectares per working adult.

\section{Social Proximity}

The focus is on dimensions of social structure that have been widely discussed in the literature. Ethnicity is included because ethnic fractionalization has been shown to be associated with aggregate outcomes (e.g., Alesina et al.2003; Alesina, Michalopoulos, and Papaioannou 2016) as well as with frictions and discrimination (e.g., Riach and Rich [2002], and the other references listed in section 2). We include kinship

18 The 2 percent of landless households who transfer out land also transfer land in-and thus end up with a nonnegative amount of land.

19 The relatively small geographical size of the villages means that soil quality is fairly uniform within each village. Hence, information asymmetries and moral hazard are probably less severe in land transactions than in labor transactions.

20 Seasonal migrant workers typically referred to as "strange farmers" were a relatively common phenomenon in rural Gambia in the past (Swindell 1987). They were not commonly found in the studied villages in 2009, however, and they do not appear in the data. 
and family ties because they have long been suspected of being a source of market inefficiency and inequality (e.g., La Ferrara 2003). Frictions caused by distance have also long been documented (e.g., Ravallion 1986; Fafchamps and Gubert 2007). These aspects of social structure may also be more amenable to policy interventions aimed at reducing discriminatory behavior. In contrast, it is unlikely that it is possible to ever totally eliminate idiosyncratic obstacles to trade due to, say, enmity between individuals.

The data contains information on three distinct aspects of pre-existing social structure: ethnicity, kinship (family ties), and geographical proximity. This data is used to construct two group-wise $D_{i j}$ and two pairwise $L_{i j}$ variables. The sample is representative of the ethnic diversity in the Gambia. The largest ethnic group (Mandinka) accounts for 54.1 percent of households in the sample (see table 3). Four other ethnic groups each account for at least 5 percent of the households. ${ }^{21}$ Since, by definition, ethnicity is shared by all the members of a group, it is captured using a group-wise variable $D_{i j}^{E}$ equal to 1 if $i$ and $j$ share the same ethnicity. In this case, each ethnic group forms a component.

Kinship, in contrast, defines a symmetric network in which a link $L_{i j}^{K}$ between two households $i$ and $j$ is defined to exist if they are related, either through the household head, through the wife(s) of the head, or through marriage. Unlike in other African contexts (e.g., Barr, Dekker, and Fafchamps 2012), kinship networks are relatively dense in the sample. Eighty-five percent of household heads and 51 percent of their wives have relatives in the village (see table 3). Similarly, 64 percent of households have marriage ties in the village. In total, 95.8 percent of households have at least one of these kinds of links. This means that the largest component of the kinship network is often large: In the majority of villages, most (though not all) households are connected, directly or indirectly, through consanguinity and marriage, and thus belong to the same network component. Component membership defines a second group-wise variable $D_{i j}^{K}$.

The dataset also contains information on whether two households reside in neighboring compounds. This information is used to define a pairwise variable $L_{i j}^{D}$ equal to 1 if $i$ and $j$ are neighbors, and 0 otherwise. Given that households live relatively close to each other, there is no natural partition of households into components, and a group-wise variable $D_{i j}^{D}$ is not defined. Data on geographical proximity were only collected in 25 of the villages, containing 624 households in total. In the reduced sample on which proximity data is available, almost 10 percent of the households are compound neighbors.

Kinship, ethnicity, and geographical distance are the dimensions of social proximity for which there is data available. They offer the advantage of being immutable or predetermined and are thus reasonably exogenous to the factor transfers taking place within an agricultural season. Nonetheless, factor transfers

Table 3. Descriptive Statistics on Ethnicity and Kinship Links

\begin{tabular}{lr}
\hline & Mean \\
\hline Ethnicity: Mandinka & $54.1 \%$ \\
Ethnicity: Fula & $18.6 \%$ \\
Ethnicity: Wollof & $10.1 \%$ \\
Ethnicity: Jola & $6.5 \%$ \\
Ethnicity: Sererr & $5.6 \%$ \\
Household head has family links in the village & $85.0 \%$ \\
Wife of household head has family links in the village & $50.8 \%$ \\
Household has marriage links in the village & $64.2 \%$ \\
Household has family links in the village & $95.8 \%$ \\
Observations & 1,625 \\
\hline
\end{tabular}

Source: Author's own calculations on the Gambia Networks Data 2009.

21 Using the Herfindahl index to measure ethnic diversity, ethnic fragmentation inside villages ranges from 0 (completely homogeneous) to 0.84 , with a mean of 0.28 . 
between two households are often embedded in long-term relationships of favor exchange that are not observed. From the available literature, it is likely that these favor exchange relationships are shaped, as least partially, by kinship, ethnicity, and geographical distance. If gift exchange transcends predetermined social categories such that they do not matter, this will show up in the analysis as zero $\alpha_{3}, \alpha_{4}$, and $\alpha_{5}$ coefficients on network regressors. Even in this case, gift exchange may still not achieve efficiency. For instance, even if people choose their network links so as to maximize gains from factor exchange, they may not be able to sustain a number of links that is sufficient to ensure equalization of factor endowments or factor ratios in all circumstances. This situation will manifest itself in the form of $\alpha_{1}$ and $\alpha_{2}$ being less than 1 . These observations form the basis for the testing strategy.

The network structure of the data gives rise to two potential problems to identification of the $\alpha$ parameters. First, in order to separate out the effects of different pre-existing networks, sufficient variation between different network measures is needed to avoid multicollinearity. A second potential identification issue relates to the need for multiple components within each village to identify component effects. In order to check this, the mean and range of the share of households who belong to the largest and second largest components of ethnicity and family ties were calculated (see supplementary online appendix S2 for statistics and additional discussion). Link correlations are sufficiently low as to not present a problem for identification. While some villages do not contribute to the identification of component parameters, many villages consist of multiple components, and this generates sufficient variation to estimate component parameters.

\section{Empirical Results}

Before launching into the estimation of the model, the available evidence regarding the redistribution of land among farming households through transfers is considered. The Gini coefficient on after-transfer household land is 0.47 , compared to 0.52 for before-transfer land endowments. More than 75 percent of villages have a more equal factor distribution after land transfers than before. The proportion of aftertransfer land in the hands of the 10 percent most land-rich households is 31 percent-down from 34 percent on average. Land transfers also tend to equalize differences in endowments across ethnic groups: After transfers, the largest ethnic group controls 1.12 times more land than members of other ethnic groups, compared to 1.2 before transfers. To conclude, transfers have, on average, an equalizing effect on the allocation of cultivable land. But the distribution of land after transfers remains fairly unequal.

As an initial check on the idea that inequality is mitigated by social structure, a set of regressions of village-level land inequality on measures of social network density are estimated (table 4). To facilitate interpretation, network density is normalized by its standard deviation. Inequality measures are calculated

Table 4. Village Land Inequality and Social Network Density

\begin{tabular}{|c|c|c|c|c|c|c|}
\hline & (1) & (2) & (3) & (4) & (5) & (6) \\
\hline & \multicolumn{3}{|c|}{ Before land transfers } & \multicolumn{3}{|c|}{ After land transfers } \\
\hline & Kinship & Ethnicity & Neighbor & Kinship & Ethnicity & Neighbor \\
\hline Density / SD & $\begin{array}{c}-0.068 * * * \\
(0.021)\end{array}$ & $\begin{array}{r}-0.019 \\
(0.023)\end{array}$ & $\begin{array}{c}-0.107 * * \\
(0.041)\end{array}$ & $\begin{array}{c}-0.038 * \\
(0.020)\end{array}$ & $\begin{array}{c}0.005 \\
(0.020)\end{array}$ & $\begin{array}{c}-0.071 \% \\
(0.035)\end{array}$ \\
\hline Constant & $\begin{array}{l}0.645 * * * \\
(0.043)\end{array}$ & $\begin{array}{l}0.572 * * * \\
(0.066)\end{array}$ & $\begin{array}{l}0.662 * * * \\
(0.077)\end{array}$ & $\begin{array}{l}0.542 * * * \\
(0.041)\end{array}$ & $\begin{array}{l}0.457^{* * * *} \\
(0.059)\end{array}$ & $\begin{array}{l}0.557 * * * \\
(0.066)\end{array}$ \\
\hline Observations & 50 & 50 & 24 & 50 & 50 & 24 \\
\hline
\end{tabular}

Source: Author's own calculations on the Gambia Networks Data 2009.

Note: OLS regressions. The dependent variable is the Gini coefficients in land in each village. It varies between zero and one. SD is the standard deviation of the density measure. $* * p<0.01, * p<0.05, * p<0.1$. 
both before and after land transfers. The results show a negative association between village network density and land inequality before transfers: More socially connected villages are more equal both before and after land transfers. This is true for both the kinship network as well as neighbor links, but this association does not hold for the ethnic components. This is somewhat surprising and is discussed in more length in connection to the link-level analysis. The effects are qualitatively unchanged if instead inequality after land transfers is considered, although the significance level is reduced. ${ }^{22}$ The estimated coefficients are small, but economically meaningful: A one-standard-deviation increase in either the kinship or neighbor density measure is associated with a decrease in the Gini coefficient of between four and 11 points, depending on the network density measure used.

Whether land transfers are more common between socially proximate households is also investigated. To this effect, $\left|w_{i j}\right|$ is regressed on the five measures of social proximity described earlier: co-ethnicity $D_{i j}^{E}$, membership in the same kinship component $D_{i j}^{K}$, being directly related $L_{i j}^{K}$, and being neighbors $L_{i j}^{D}$. Results show that $D_{i j}^{E}$ and $D_{i j}^{K}$ do not predict land transfers, but $L_{i j}^{K}$ and $L_{i j}^{D}$ do, suggesting homophily in land transactions along those two dimensions (see table 5). ${ }^{23}$

The situation can thus be summarized as follows: An essential resource is not allocated equitably between small producers, a situation there are reasons to suspect is inefficient; the dominant ethnic group in a village owns more land; inequality in land and factor ratios is lower in more socially connected villages; and farmers who are neighbors or directly related share more land with each other. To many, this type of evidence is a smoking gun suggesting that preferential transfers between members of the land-rich dominant ethnic group contribute to the unequal land allocation. The purpose of the testing strategy is to put this reasoning to the test.

First, the various models outlined in section 2 on land transfers alone are estimated. The main reason for focusing on land is that as noted above, land transfers are much more important than labor transfers in terms of the proportion of traded factors.

Table 5. Land Transfers and Social Proximity

\begin{tabular}{|c|c|c|c|c|c|}
\hline & (1) & (2) & (3) & (4) & $(5)$ \\
\hline Ethnic component & $\begin{array}{c}0.000 \\
(0.001)\end{array}$ & & & & $\begin{array}{c}-0.001 \\
(0.005)\end{array}$ \\
\hline Family component & & $\begin{array}{r}-0.005 \\
(0.008)\end{array}$ & & & $\begin{array}{r}-0.002 \\
(0.009)\end{array}$ \\
\hline Family link & & & $\begin{array}{l}0.045 * * * \\
(0.009)\end{array}$ & & $\begin{array}{l}0.045^{* * *} \\
(0.010)\end{array}$ \\
\hline Neighbor link & & & & $\begin{array}{l}0.035 * * * \\
(0.011)\end{array}$ & $\begin{array}{l}0.026 * * \\
(0.010)\end{array}$ \\
\hline Constant & $\begin{array}{l}0.037 * * * \\
(0.006)\end{array}$ & $\begin{array}{l}0.041 * * * \\
(0.008)\end{array}$ & $\begin{array}{l}0.031 * * * \\
(0.005)\end{array}$ & $\begin{array}{l}0.023 * * * \\
(0.004)\end{array}$ & $\begin{array}{l}0.020 * * \\
(0.007)\end{array}$ \\
\hline Observations & 54,144 & 54,144 & 54,144 & 21,266 & 21,266 \\
\hline
\end{tabular}

Source: Author's own calculations on the Gambia Networks Data 2009.

Note: OLS regressions where the dependent variable is the absolute amount of land transferred from $i$ to $j$ measured in hectares. Standard errors clustered by village are shown in parentheses. $* * p<0.01, * * p<0.05, * p<0.1$.

22 This is perhaps not surprising: The same underlying factors that facilitate short-term land transfers may also facilitate permanent land transfers between households-for example, through inheritance and transfers inter vivos at the time of marriage.

23 Virtually identical results are obtained if the dependent variable is replaced by a dummy equal to 1 if $\left|w_{i j}\right|>0$ and 0 otherwise. 
A fair approximation of the data is that land transfers are used to determine the size of one's farm ex ante, while labor transfers are used to deal with temporary surpluses and deficits in labor ex postfor example, in response to unforeseen shocks in the production process (Fafchamps 1993). To verify the robustness of the findings, in the next subsection we replicate the analysis in terms of land-labor ratio. As discussed in the conceptual section and demonstrated in the supplementary online appendix, the methodology can similarly be applied using land-labor ratios in lieu of land endowments to allow for possible trade in labor.

\section{Land Transfers}

First, whether land transfers eliminate differences in land endowments is tested. This is achieved by estimating the simplest model (2). The average land endowment $\bar{a}$ is calculated as the sum of all land endowments divided by the number of households in the village. ${ }^{24}$ Since the regression is dyadic, standard errors must be corrected for non-independence across observations. To deal with this issue, standard errors are clustered at the village level. This allows for any correlation structure between errors within each village, including the type of network error correlation discussed in Fafchamps and Gubert (2007).

The fact that $\alpha_{1}$ is positive and statistically significant implies that land-abundant farmers on average transfer out land, while land-poor households import land from others (see table 6). But these transfers are not sufficient to equalize land across households within each village: The test $\alpha_{1}=\alpha_{2}=1$ is strongly rejected with $p<0.0001$. This particular finding is vulnerable to measurement error in $a_{i}$, which is expected to generate attenuation bias. It follows that $\widehat{\alpha}_{1}$ and $\widehat{\alpha}_{2}$ should probably best be seen as a lower bound on the true coefficients. Still, point estimates are only a small percentage of what would be required for land equalization, suggesting that attenuation bias is unlikely to account for the rejection of perfect equalization.

Next, whether there are more equalizing land transfers between members of the same ethnic group or kinship component is examined, that is, for $D_{i j}^{E}$ and $D_{i j}^{K}$, respectively. Estimation results for regression model (4) indicate that transfers achieve less equalization of land area within ethnic groups (table 6, column 2) or kinship components (table 6, column 3) than they achieve across the villages as a

Table 6. One-Factor Model: Do Social Components Equalize Farm Size?

\begin{tabular}{|c|c|c|c|c|c|c|}
\hline Regressor & Coefficient & (1) & $\begin{array}{c}(2) \\
\text { Ethnicity }\end{array}$ & $\begin{array}{c}(3) \\
\text { Kinship }\end{array}$ & $\begin{array}{c}(4) \\
\text { Ethnicity }\end{array}$ & $\begin{array}{c}(5) \\
\text { Kinship }\end{array}$ \\
\hline$\frac{\left(a_{i}-\bar{a}\right)}{N_{v}}$ & $\alpha_{1}$ & $\begin{array}{l}0.024 * * \\
(0.009)\end{array}$ & & & $\begin{array}{l}0.032 * * * \\
(0.011)\end{array}$ & $\begin{array}{l}0.0510 * * * \\
(0.016)\end{array}$ \\
\hline$\frac{\left(\bar{a}-a_{i}\right)}{N_{v}}$ & $\alpha_{2}$ & $\begin{array}{l}0.024 * * \\
(0.009)\end{array}$ & & & $\begin{array}{l}0.032 * * * \\
(0.011)\end{array}$ & $\begin{array}{l}0.051^{* * *} \\
(0.016)\end{array}$ \\
\hline$\frac{\left(a_{i}-\bar{a}_{k}\right)}{N_{v}} D_{i j}$ & $\alpha_{3}$ & & $\begin{array}{l}0.015 * * \\
(0.006)\end{array}$ & $\begin{array}{l}0.017 * * \\
(0.007)\end{array}$ & $\begin{array}{c}-0.009 * \\
(0.005)\end{array}$ & $\begin{array}{c}-0.029 * * * \\
(0.010)\end{array}$ \\
\hline$\frac{\left(\bar{a}_{k}-a_{j}\right)}{N_{v}} D_{i j}$ & $\alpha_{4}$ & & $\begin{array}{l}0.015 * * \\
(0.006)\end{array}$ & $\begin{array}{l}0.017 * * \\
(0.007)\end{array}$ & $\begin{array}{c}-0.009 * \\
(0.005)\end{array}$ & $\begin{array}{c}-0.029 * * * \\
(0.010)\end{array}$ \\
\hline Constant & $\alpha_{0}$ & 0 & 0 & 0 & 0 & 0 \\
\hline Observations & & 54,144 & 54,144 & 54,144 & 54,144 & 54,144 \\
\hline
\end{tabular}

Source: Author's own calculations on the Gambia Networks Data 2009.

Note: OLS regressions where the dependent variable is the amount of land transferred from $i$ to $j$ measured in hectares. Standard errors clustered by village are shown in parentheses. ${ }^{* * *} p<0.01, * p<0.05, * p<0.1$.

24 The dataset also includes information about land transfers to and from households outside the village. To avoid biasing the testing strategy, these transfers are netted out before calculating $\bar{a}$. 
whole: $\widehat{\alpha}_{3}<\widehat{\alpha}_{1}$ in both cases. This is a first indication that land transfers do not operate primarily within ethnic or kinship groupings.

In columns 4 and 5, both sets of regressors are combined and estimate the joint model (6), repeated here for convenience:

$$
\begin{aligned}
w_{i j}= & \alpha_{0}+\alpha_{1} \frac{a_{i}-\bar{a}_{v}}{N_{v}}+\alpha_{2} \frac{\bar{a}_{v}-a_{j}}{N_{v}} \\
& +\alpha_{3} \frac{a_{i}-\bar{a}_{k}}{N_{k}} D_{i j}+\alpha_{4} \frac{\bar{a}_{k}-a_{j}}{N_{k}} D_{i j}+u_{i j} .
\end{aligned}
$$

Positive coefficient estimates are obtained for $\alpha_{1}$ (and $\alpha_{2}$ ) but negative coefficient estimates for $\alpha_{3}$ (and $\alpha_{4}$ ). As shown in the simulation results presented in supplementary online appendix S3, this outcome arises when transfers serve to equalize land across the whole village. ${ }^{25}$ This confirms that there is no more land equalization within ethnic or kinship groups than across the entire village. In other words, ethnicity and kinship are not what drives the lack of land equalization in the village. This is consistent with Arcand and Jaimovich (2014), who also conclude that ethnic divisions do not reduce land transfers in the Gambia Networks Data 2009.

One possible interpretation of these findings is that lineage heads, who are entrusted with the land of their lineage, choose to co-opt newcomers into the village by granting them secondary or temporary rights on land. Since these newcomers often are from a different ethnic and kinship group, this means that sizable land transfers take place across ethnic and kinship boundaries. If land transfers from these outliers are ignored, more evidence of land equalization within ethnic and kinship groups may be found.

To verify this interpretation, the regressions are estimated without land-rich outliers. In practice, outliers are winsorized by replacing values of $\left(a_{i}-\bar{a}_{k}\right) / N_{k}$ and $\left(\bar{a}_{k}-a_{j}\right) / N_{k}$ below the first percentile and above the 99th percentile with the value of the first and the 99th percentile, respectively. Two findings come out of this exercise (see supplementary online appendix S2). First, when estimating regression model (4) (columns 1 and 2), point estimates for $\alpha_{3}$ and $\alpha_{4}$ increase markedly: They more than double for ethnicity and nearly double for kinship. This suggests that when transfers from outliers are omitted from the analysis, the rest of the transfers within co-ethnic or kin farmers serve a more effective role in withingroup land equalization. However, when model (6) is estimated, again negative estimates for $\alpha_{3}$ and $\alpha_{4}$ (albeit not significantly so in the case of co-ethnicity) and positive estimates for $\alpha_{1}$ and $\alpha_{2}$ are found. This indicates that the negative coefficients found in table 6 are not purely due to large land owners: Even smaller land owners share land across ethnic or kinship boundaries.

Next, direct kinship links between households $L_{i j}^{K}$ are introduced, and model (5) is estimated. Results show that $\widehat{\alpha}_{5}$ is positive and statistically significant, suggesting that land transfers between directly related households tend to equalize their respective land areas (see column 1 of table 7). The point estimate is very small, however: approximately 0.2 percent of the transfers that would be necessary to equalize landholdings between related households. Once village regressors $\frac{a_{i}-\bar{a}_{v}}{N_{v}}$ and $\frac{\bar{a}_{v}-a_{i}}{N_{v}}$ are added, the finding disappears, as shown in column 2. Again, the interpretation is that land transfers are better predicted by differences from the village average than by pairwise differences across related households.

In the last two columns of table 7 , geographical proximity $L_{i j}^{D}$ is considered. As explained earlier, data on compound neighbors only exist for a subset of households, hence the drop in the total number of observations. When the only regressor is the pairwise land difference between neighbors, a positive and significant $\alpha_{5}$ estimate is found, suggesting that land transfers between neighbors on average go in the direction of equalizing their respective land areas. Unlike in the case of related households, this finding survives adding village regressors $\frac{a_{i}-\bar{a}_{v}}{N_{v}}$ and $\frac{\bar{a}_{v}-a_{i}}{N_{v}}$ : Point estimates for $\alpha_{1}$ and $\alpha_{2}$ remain large and comparable to those obtained in column 2 , but they are not statistically significant. In contrast, $\widehat{\alpha}_{5}$ remains

25 Point estimates $\alpha_{3}$ and $\alpha_{4}$ turn negative in this case because average land endowments differ across ethnic groups, and land equalization within the village means moving away from land equalization within ethnic or kinship groupings. 
Table 7. One-Factor Model: Do Direct Links Equalize Farm Size?

\begin{tabular}{|c|c|c|c|c|c|}
\hline Regressor & Coefficient & $\begin{array}{c}(1) \\
\text { Kinship }\end{array}$ & $\begin{array}{c}(2) \\
\text { Kinship }\end{array}$ & $\begin{array}{c}(3) \\
\text { Neighbor }\end{array}$ & $\begin{array}{c}(4) \\
\text { Neighbor }\end{array}$ \\
\hline$\frac{\left(a_{i}-\bar{a}\right)}{N_{v}}$ & $\alpha_{1}$ & & $\begin{array}{l}0.021 * * \\
(0.010)\end{array}$ & & $\begin{array}{c}0.025 \\
(0.022)\end{array}$ \\
\hline$\frac{\left(\bar{a}-a_{j}\right)}{N_{v}}$ & $\alpha_{2}$ & & $\begin{array}{l}0.021 * * \\
(0.010)\end{array}$ & & $\begin{array}{c}0.025 \\
(0.022)\end{array}$ \\
\hline$\frac{\left(a_{i}-a_{j}\right)}{2} L_{i j}$ & $\alpha_{5}$ & $\begin{array}{l}0.002 * * \\
(0.001)\end{array}$ & $\begin{array}{c}0.001 \\
(0.001)\end{array}$ & $\begin{array}{c}0.007^{*} \\
(0.004)\end{array}$ & $\begin{array}{c}0.005^{*} \\
(0.003)\end{array}$ \\
\hline Constant & $\alpha_{0}$ & 0 & 0 & 0 & 0 \\
\hline Observations & & 54,144 & 54,144 & 21,266 & 21,266 \\
\hline
\end{tabular}

Source: Author's own calculations on the Gambia Networks Data 2009.

Note: OLS regressions where the dependent variable is the amount of land transferred from $i$ to $j$ measured in hectares. Standard errors clustered by village are shown in parentheses. $* * p<0.01, * * p<0.05, * p<0.1$.

statistically significant, weakly suggesting that land transfers serve more the role of land equalization between neighbors than land equalization within the village. It is not possible, however, to reject the hypothesis that $\alpha_{1}$ and $\alpha_{2}$ are equal to the estimates reported in column 2 . Furthermore, point estimates remain well below 1 throughout, indicating that perfect equalization is far from achieved.

To conclude, land transfers on average go in the direction of equalizing land across all households in the village, although the effect is small in magnitude-a result that is in agreement with the earlier finding that the Gini coefficient of land drops from 0.52 to 0.47 after transfers, a modest improvement. There is no evidence that there is more equalization of land area within ethnic or kinship group than across the village as a whole. This finding remains even when large landowners, whose social role includes welcoming newcomers into the village by offering them some land to cultivate on a temporary basis, are removed. This implies that land transfers generally occur across ethnic and kinship boundaries. When close links between neighbors and between directly related households are considered, we find evidence that land transfers go in the direction of equalizing landholdings between them. But for direct kinship links, the effect disappears once village-level regressors are included. In contrast, there is evidence that land transfers between neighbors serve to equalize their respective landholdings over and above their role in equalizing landholdings at the village level. Coefficient estimates are well below 1 in all cases, however, indicating that equalization is far from achieved in any of the considered cases.

\section{Factor Ratios}

As explained in the conceptual section, land equalization need not be efficient if farmers differ in productivity. If productivity differences are Hicks-neutral and labor is tradable, however, factor ratios should be equalized across farms. To investigate this possibility, a test is performed of whether land transfers serve to equalize the land-labor ratio $r_{i}$ across farms and, more importantly, whether social structure is an impediment to such equalization at the village level. To this effect, the same analysis using land-labor ratios $r_{i}$ in lieu of land endowments $a_{i}$ is performed.

The first set of results is presented in table 8, which mirrors table 6. Results are qualitatively similar, but point estimates are larger-albeit still well below 1. As before, equalization within villages trumps equalization within ethnic or kinship groups: Point estimates $\alpha_{3}$ and $\alpha_{4}$ become negative once village-level regressors $\frac{r_{i}-\bar{r}_{v}}{N_{v}}$ and $\frac{\bar{r}_{v}-r_{i}}{N_{v}}$ are included. In results not shown here to save space, the winsorization exercise conducted on the one-factor model is repeated. Results are qualitatively identical, albeit with larger point estimates. Table 9 mirrors table 7 , with the inclusion of direct kinship or neighbor links between household pairs. Results are again similar to those presented earlier. 
Table 8. Two-Factor Model: Do Social Components Equalize Farm Size?

\begin{tabular}{|c|c|c|c|c|c|c|}
\hline Regressor & Coefficient & (1) & $\begin{array}{c}(2) \\
\text { Ethnicity }\end{array}$ & $\begin{array}{c}(3) \\
\text { Kinship }\end{array}$ & $\begin{array}{c}(4) \\
\text { Ethnicity }\end{array}$ & $\begin{array}{c}(5) \\
\text { Kinship }\end{array}$ \\
\hline$\frac{(r-\bar{r})}{N_{v}}$ & $\alpha_{1}$ & $\begin{array}{l}0.065 * * * \\
(0.021)\end{array}$ & & & $\begin{array}{l}0.089 \% * * \\
(0.029)\end{array}$ & $\begin{array}{l}0.152 * * * \\
(0.037)\end{array}$ \\
\hline$\frac{\left(\bar{r}-r_{j}\right)}{N_{v}}$ & $\alpha_{2}$ & $\begin{array}{l}0.065^{* * *} \\
(0.021)\end{array}$ & & & $\begin{array}{l}0.089 * * * \\
(0.029)\end{array}$ & $\begin{array}{l}0.152 * * * \\
(0.037)\end{array}$ \\
\hline$\frac{\left(r_{i}-\bar{r}_{k}\right)}{N_{v}} D_{i j}$ & $\alpha_{3}$ & & $\begin{array}{l}0.037 * * * \\
(0.013)\end{array}$ & $\begin{array}{l}0.045 * * * \\
(0.015)\end{array}$ & $\begin{array}{r}-0.026^{*} \\
(0.013)\end{array}$ & $\begin{array}{c}-0.090 * * * \\
(0.023)\end{array}$ \\
\hline$\frac{\left(\bar{r}_{k}-r_{j}\right)}{N_{v}} D_{i j}$ & $\alpha_{4}$ & & $\begin{array}{l}0.037 * * * \\
(0.013)\end{array}$ & $\begin{array}{l}0.045 * * * \\
(0.015)\end{array}$ & $\begin{array}{r}-0.026 \% \\
(0.013)\end{array}$ & $\begin{array}{c}-0.090 * * * \\
(0.023)\end{array}$ \\
\hline Constant & $\alpha_{0}$ & 0 & 0 & 0 & 0 & 0 \\
\hline Observations & & 54,144 & 54,144 & 54,144 & 54,144 & 54,144 \\
\hline
\end{tabular}

Source: Author's own calculations on the Gambia Networks Data 2009.

Note: OLS regressions where the dependent variable is the amount of land transferred from $i$ to $j$ measured in hectares. Standard errors clustered by village are shown in parentheses. ${ }^{* * *} p<0.01, * * p<0.05, * p<0.1$.

Table 9. Two-Factor Model: Do Direct Links Equalize Farm Size?

\begin{tabular}{|c|c|c|c|c|c|}
\hline Regressor & Coefficient & $\begin{array}{c}(1) \\
\text { Kinship }\end{array}$ & $\begin{array}{c}(2) \\
\text { Kinship }\end{array}$ & $\begin{array}{c}(3) \\
\text { Neighbor }\end{array}$ & $\begin{array}{c}(4) \\
\text { Neighbor }\end{array}$ \\
\hline$\frac{(r-\bar{r})}{N_{v}}$ & $\alpha_{1}$ & & $\begin{array}{l}0.061 * \\
(0.023)\end{array}$ & & $\begin{array}{l}0.058 \\
(0.070)\end{array}$ \\
\hline$\frac{\left(\bar{r}-r_{j}\right)}{N_{v}}$ & $\alpha_{2}$ & & $\begin{array}{l}0.061 * * \\
(0.023)\end{array}$ & & $\begin{array}{l}0.058 \\
(0.070)\end{array}$ \\
\hline$\frac{\left(r_{i}-r_{j}\right)}{2} L_{i j}$ & $\alpha_{5}$ & $\begin{array}{l}0.005 * * \\
(0.002)\end{array}$ & $\begin{array}{l}0.002 \\
(0.003)\end{array}$ & $\begin{array}{l}0.017^{*} \\
(0.010)\end{array}$ & $\begin{array}{l}0.014 * \\
(0.008)\end{array}$ \\
\hline Constant & $\alpha_{0}$ & 0 & 0 & 0 & 0 \\
\hline Observations & & 54,144 & 54,144 & 21,266 & 21,266 \\
\hline
\end{tabular}

Source: Author's own calculations on the Gambia Networks Data 2009.

Note: OLS regressions where the dependent variable is the amount of land transferred from $i$ to $j$ measured in hectares. Standard errors clustered by village are shown in parentheses. ${ }^{* * *} p<0.01, * * p<0.05, * p<0.1$.

To conclude, results regarding factor ratio equalization are quite similar to those of land equalization: Land transfers on average go in the direction of factor ratio equalization but fall far short of achieving it in full. We do not, however, find that this failure is driven by a propensity to equalize factor ratios primarily within ethnic or kinship groups, or between directly related households. There is, however, some evidence that neighbors share land to even out their factor ratio differences over and above what is explained by village-wide equalization.

\section{Labor Transfers}

Land transfers are not the only margin that can be used to equalize factor ratios across households. Another option is to adjust the amount of labor during the cropping season. To formally examine this, labor transfers of household heads are used as the dependent variable $w_{i j}$ and estimate a model of the form:

$$
w_{i j}=\beta_{0}+\beta_{1} \frac{\left(r_{i}-\bar{r}\right)}{N_{v}}+\beta_{2} \frac{\left(\bar{r}-r_{j}\right)}{N_{v}}+u_{i j}
$$

This model can be extended similarly to models (4) and (5). Labor transfers that improve allocative efficiency require negative parameter estimates: Labor $l$ should on average flow from agents with a low land-labor endowment ratios $r_{i}$ to agents with high land-labor ratios relative to the village average $\bar{r}$. 
There is no evidence that labor transfers equalize factor ratios: The only parameter of statistical significance is the kinshop link parameter, and it is of the opposite sign (positive) than what is required for family links to positively impact the factor-equalizing properties of labor transfers (table 10). These findings suggest that labor transfers do not help equalize ex ante factor ratios in the studied villages. Given the timing of labor transfers- that is, after cultivation rights have been allocated and planting has begun-the logical conclusion is that labor transfers primarily serve as an ex post adjustment to labor shocks. ${ }^{26}$

If labor transfers are only used as an ex post adjustment to labor shocks during peak season, cultivated land can be taken as predetermined at the time these transfers take place. Given this, it may be useful to re-estimate model (9) using land-labor ratios calculated using cultivated land in lieu of owned land. ${ }^{27}$ Results are very similar to those reported in table 10 .

Table 10. Do Labor Transfers Equalize Farm Size?

\begin{tabular}{|c|c|c|c|c|c|c|}
\hline Regressor & Coefficient & (1) & $\begin{array}{c}(2) \\
\text { Ethnicity }\end{array}$ & $\begin{array}{c}(3) \\
\text { Kinship }\end{array}$ & $\begin{array}{c}(4) \\
\text { Kinship }\end{array}$ & $\begin{array}{c}(5) \\
\text { Neighbor }\end{array}$ \\
\hline$\frac{(r-\bar{r})}{N_{V}}$ & $\alpha_{1}$ & $\begin{array}{c}0.000 \\
(0.000)\end{array}$ & & & & \\
\hline$\frac{\left(\bar{r}-r_{j}\right)}{N_{v}}$ & $\alpha_{2}$ & $\begin{array}{c}0.000 \\
(0.000)\end{array}$ & & & & \\
\hline$\frac{\left(r_{i}-\bar{r}_{k}\right)}{N_{v}} D_{i j}$ & $\alpha_{3}$ & & $\begin{array}{c}0.000 \\
(0.000)\end{array}$ & $\begin{array}{c}0.000 \\
(0.000)\end{array}$ & & \\
\hline$\frac{\left(\bar{r}_{k}-r_{j}\right)}{N_{v}} D_{i j}$ & $\alpha_{4}$ & & $\begin{array}{c}0.000 \\
(0.000)\end{array}$ & $\begin{array}{c}0.000 \\
(0.000)\end{array}$ & & \\
\hline$\frac{\left(r_{i}-r_{j}\right)}{2} L_{i j}$ & $\alpha_{5}$ & & & & $\begin{array}{l}0.005 * * \\
(0.001)\end{array}$ & $\begin{array}{r}-0.000 \\
(0.000)\end{array}$ \\
\hline Constant & $\alpha_{0}$ & 0 & 0 & 0 & 0 & 0 \\
\hline Observations & & 54,144 & 54,144 & 54,144 & 54,144 & 21,266 \\
\hline
\end{tabular}

Source: Author's own calculations on the Gambia Networks Data 2009.

Note: OLS regressions where the dependent variable is the amount of household head labor transfered from $j$ to $i$, measured in working days. Standard errors clustered by village are shown in parentheses. ${ }^{* *} p<0.01, * p<0.05, * p<0.1$.

\section{Discussion}

This paper has examined whether social structure affects the equalization of factors and factor ratios across farming households. With some additional assumptions, the absence of equalization can be seen as implying a failure to allocate factors of production efficiently. How convincing is this conclusion? As noted in the conceptual section, whether or not inequality in cultivated acreage or factor ratios signals allocative inefficiency hinges on two maintained assumptions that cannot be substantiated with the data at hand: decreasing returns to scale; and unobserved productivity differences. These are discussed in turn.

The possible existence of increasing returns to scale in tropical farming cannot be ruled out, and indeed a number of tropical countries have (or have had) large successful commercial farms-including Liberia, which lies in West Africa like the Gambia. These commercial farms, however, rely on technological and organizational innovations that are out of reach of the predominantly illiterate farmers residing in the study villages. Successful use of animal traction requires a minimum scale of production, but this scale is well within the realm of the smallholder farmers in our study. Using a simple replication argument,

26 Results of the combined models (6) and (7) are not shown in order to save space. Results closely resemble the reported results: Labor does not appear to play a factor-equalizing role.

27 In results not shown here, this possibility was investigated by defining $\tilde{r}_{i} \equiv \frac{\tilde{a}_{i}}{l_{i}}$ where $\tilde{a}_{i}$ is the land in the hands of farmer $i$ after all land transfers have taken place. If labor transfers serve to equalize factor rations ex post, labor should on average flow from agents with a low $\tilde{r}_{i}$ to those with a high $\tilde{r}_{i}$ relative to the village average $\bar{r}$. 
one may conclude that traditional farming is characterized by constant returns to scale in land and labor. While this argument is not without merit, it is widely recognized that hired labor is subject to various moral hazard considerations that create a wedge between the productivity of labor on one's own farm or someone else's. This is particularly true in West Africa because agrarian sharing norms tend to delegitimate efforts to hire large number of agricultural laborers (Platteau, Hayami, and Dasgupta 1998). In the context of our study population, decreasing returns to scale are a therefore reasonable assumption, substantiated by much existing data on smallholder farming in African and elsewhere (e.g., Deininger and Feder 2000; Ali and Deininger 2015).

To circumvent the possible existence of unobserved productivity differences, the methodology was applied to factor ratios which, if productivity differences are Hicks-neutral, should be equalized to achieve allocative efficiency. Land transfers do not equalize ex ante land-labor ratios, and labor transfers do not equalize ex ante or ex post factor ratios. The conclusion that follows from this evidence is that factors of production are not efficiently allocated, so as to match possible Hicks-neutral differences in productivity across farmers.

There remains the possibility that productivity differences across farmers are factor-biased. If some farmers have a higher land productivity than others, ${ }^{28}$ they can be expected to have a higher land-labor ratio. The authors of this paper suspect that unobservable productivity differences matter more in modern agriculture, and less in traditional subsistence agriculture, which is fairly undifferentiated and follows simple heuristic rules of behavior. In the study area, factor-biased productivity differences would have to be large to explain a Gini coefficient of 0.47 in land available for cultivation-given how thin agricultural labor markets are in the study area. Furthermore, unless land and labor are near-perfect substitutes in production-which is unlikely-much larger labor transactions from land-poor to land-rich (and presumably highly productive) farmers should be observed. However, this is not what is observed with the current data: Labor flows hardly respond to differences in ex ante or ex post factor ratios. Finally, Chavas, Petrie, and Roth (2005) find evidence that technical inefficiency among Gambian farmers is modest and that differences in factor mix are not driven by technological differences. The authors nonetheless find substantial allocative inefficiency in farm input allocation, which motivates the focus of the present paper.

While these arguments militate against the idea that productivity differences account for the data, it cannot be fully ruled out. To provide evidence about the possible extent of the issue, regression models (2), (4), and (5) are re-estimated with additional controls for possible differences in factor-biased productivity across farmers. The main findings of the models do not change when household characteristics are included (see supplementary online appendix S2 for results and further discussion). In sum, the evidence fails to provide support for the conjecture that productivity differences are the primary driver of variation in land endowment across households in the study area.

\section{Conclusion}

In this paper, it was examined whether observable dimensions of social structure hinder or facilitate factor equalization in rural Gambia. Land ownership is highly unequal in the surveyed villages in spite of being populated by largely illiterate smallholders practicing a traditional form of agriculture. Furthermore, labor transactions, though common, only represent a small share of total available labor. In this context, factor transactions can improve the efficiency of factor allocation by reducing disparities in factor usage and factor ratios across farms.

28 And land and labor are strong substitutes, that is, the elasticity of substitution between them is more than 1 . If the production function is (approximately) Cobb-Douglas, factor-specific productivity shifters factor out of the land and labor aggregates and are observationally equivalent to Hicks-neutral productivity differences. 
In village economies, it is common to observe that many economic transactions take place along more socially proximate households. This is also what we find in the data at hand. This suggests that it is easier to equalize factor allocations within social groupings or between kin and neighbors. The question that is investigated is whether frictions in factor transfers restrict factor equalization across socially distant households and groups.

To our knowledge, this paper constitutes the first attempt to formally investigate this issue at the level of the aggregate village economy. We introduce a novel way of testing whether social and geographical distance reduces the likelihood of equalizing factor transfers. The data requirements for this approach are severe: Information on factor endowments, exhaustive pairwise information about factor transfers, and data on relevant aspects of the social structure are needed. Using such data for a large number of villages in the Gambia, the approach is implemented empirically.

The results support the hypothesis that land transfers lead to a more equal distribution of land and to more comparable factor ratios across farms. But complete equalization is far from achieved. Contrary to expectations, equalizing transfers of land are not more likely within ethnic groups or kinship groupsif anything, the opposite result is found. This finding survives when land transfers originating from a small number of households with large landholdings, whose social role is to welcome newcomers with some land, are omitted. There is also some evidence that land transfers between neighbors perform a factor-equalizing function over and above that occurring at the village level, suggesting that land-poor households may benefit from proximity to land-rich households. In contrast, there is no evidence that labor transfers serve to equalize factor allocation, either ex ante or ex post. Their role is probably to deal with unanticipated shocks-on which there is no information available in the dataset at hand.

The methodology presented in this paper has many other potential applications to study the extent to which the absence of equalization-for example, in prices, costs, access, or opportunities-is due to preferential linking or its converse, discrimination. A number of these examples are presented in the supplementary online appendix. The method requires extensive information about dyadic flows and sufficient information about social structure. Until not so long ago, this type of information would have been hard to come by. Today, however, exhaustive datasets on flows and links are becoming more commonly available, extending the relevance of the method.

The method has some inherent limitations, at least in its current form. The focus is on flows and obstacles to flows, not on the form that flows take (e.g., market or non-market exchange) or on the motivation for these flows (e.g., mutual assistance or self-interest). For instance, the empirical results do not imply that the perceived motive for land transfers is to equalize factor ratios or to increase efficiency. It is more likely that transfers are seen as a way of helping poor households and are given out of a sense of civic duty (Beck and Bjerge 2017), ${ }^{29}$ or because it is more cost-effective to transfer land to a poor household ex ante rather than transfer food and cash ex post (Fafchamps 1992). No matter the intent behind land transfers, the end result is the same: Transferring land to a land-poor household leads to a more egalitarian allocation of factors which, in a world of decreasing returns to scale, increases allocative efficiency.

\section{References}

African Development Bank 2005. “Appraisal Report: Farmer Managed Rice Project.” Agricultural and Rural Development Department, Central and West Regions, African Development Bank Group, Tunis, Tunisia.

Alesina, A., A. Devleeschauwer, W. Easterly, S. Kurlat, and R. Wacziarg. 2003. "Fractionalization.” Journal of Economic Growth 8 (2): 155-94.

29 Using the same dataset, Jaimovich (2011) finds that differences in realized income inequality across villages are correlated with transfers of inputs and credit—-though not of land. 
Alesina, A., S. Michalopoulos, and E. Papaioannou. 2016. "Ethnic Inequality.” Journal of Political Economy 124 (2): 428-88.

Alfaro, L., A. Charlton, and F. Kanczuk. 2008. "Plant-Size Distribution and Cross-Country Income Differences." Technical Report, National Bureau of Economic Research, Cambridge, MA.

Ali, D. A., and K. Deininger. 2015. "Is There a Farm Size-Productivity Relationship in African Agriculture? Evidence from Rwanda." Land Economics 91 (2): 317-43.

Allen, D. W., and D. Lueck. 1998. “The Nature of the Farm.” Journal of Law and Economics 41 (2): $343-86$.

Arcand, J.-L., and D. Jaimovich. 2014. "Does Ethnic Diversity Decrease Economic Interactions? Evidence from Exchange Networks in Rural Gambia.” MPRA Paper No. 60497, Munich Personal RePEc Archive, Munich.

Attanasio, O., A. Barr, J. C. Cardenas, G. Genicot, and C. Meghir. 2012. "Risk Pooling, Risk Preferences, and Social Networks." American Economic Journal: Applied Economics 4 (2): 134-67.

Barr, A., M. Dekker, and M. Fafchamps. 2012. "Who Shares Risk with Whom under Different Enforcement Mechanisms?” Economic Development and Cultural Change 10 (4): 677-706.

Beck, U., and B. Bjerge. 2017. "Pro-Poor Land Transfers and the Importance of Land Abundance and Ethnicity in the Gambia.” World Development 99: 122-40.

Bertrand, M., and S. Mullainathan. 2004. "Are Emily and Greg More Employable Than Lakisha and Jamal? A Field Experiment on Labor Market Discrimination.” American Economic Review 94 (4): 991-1013.

Bramoullé, Y., and R. Kranton. 2007. "Risk-Sharing Networks.” Journal of Economic Behavior \& Organization 64 (3): 275-94.

Carlsson, M., and D.-O. Rooth. 2007. "Evidence of Ethnic Discrimination in the Swedish Labor Market Using Experimental Data." Labour Economics 14 (4): 716-29.

Chaney, T. 2014. "The Network Structure of International Trade.” American Economic Review 104 (11): 3600-3634. Chavas, J.-P., R. Petrie, and M. Roth. 2005. "Farm Household Production Efficiency: Evidence from the Gambia." American Journal of Agricultural Economics 87 (1): 160-79.

de Janvry, A., M. Fafchamps, and E. Sadoulet. 1991. "Peasant Household Behaviour with Missing Markets: Some Paradoxes Explained.” Economic Journal 101 (409): 1400-1417.

Deininger, K., and G. Feder. 2001. "Land Institutions and Land Markets.” In Handbook of Agricultural Economics vol. 1A, edited by B. L. Gardner and G. C. Rausser, 287-331. Netherlands: Elsevier Science.

Dey, J. 1982. “Development Planning in the Gambia: The Gap between Planners' and Farmers' Perceptions, Expectations and Objectives." World Development 10 (5): 377-96.

Eastman, C. 1990. “Gambian Usufruct Tenure: Help or Hindrance to Agricultural Production?” Land Use Policy 7 (1): 27-40.

Edelman, B., M. Luca, and D. Svirsky. 2017. "Racial Discrimination in the Sharing Economy: Evidence from a Field Experiment." American Economic Journal: Applied Economics 9 (2): 1-22.

Fafchamps, M. 1992. "Solidarity Networks in Preindustrial Societies: Rational Peasants with Moral Economy.” Economic Development and Cultural Change 41 (1): 147-74.

Fafchamps, M. 1993. "Sequential Labor Decisions under Uncertainty: An Estimable Household Model of WestAfrican Farmers.” Econometrica 61 (5): 1173-97. Netherlands: Elsevier Science.

Fafchamps, M., and F. Gubert. 2007. “The Formation of Risk Sharing Networks.” Journal of Development Economics 83 (2): 326-50.

Fafchamps, M., and S. Lund. 2003. "Risk-Sharing Networks in Rural Philippines.” Journal of Development Economics 71 (2): 261-87.

Foulds, L. R. 1992. Graph Theory Applications. Ann Arbor, MI: Springer-Verlag.

Freudenberger, M. S. 2000. "Tenure and Natural Resources in the Gambia: Summary of Research Findings and Policy Options.” Working Paper No. 40, Land Tenure Center, University of Wisconsin-Madison, Madison, WI.

Goldin, C., and C. Rouse. 2000. "Orchestrating Impartiality: The Impact of 'Blind' Auditions on Female Musicians.” American Economic Review 90 (4): 715.

Granovetter, M. 1995. Getting a Job: A Study of Contacts and Careers. Chicago: University of Chicago Press.

Hanson, A., and Z. Hawley. 2011. "Do Landlords Discriminate in the Rental Housing Market? Evidence from an Internet Field Experiment in US Cities.” Journal of Urban Economics 70 (2): 99-114.

Holden, S., and H. Ghebru. 2005. "Kinship Transaction Costs and Land Rental Market Participation.” Department of Economics and Resource Management. Working paper. Norwegian University of Life Sciences. 
Holden, S. T., K. Otsuka, and F. Place, eds. 2009. The Emergence of Land Markets in Africa: Impacts on Poverty, Equity, and Efficiency. Washington, DC: Resources for the Future.

Hsieh, C.-T., and P. J. Klenow. 2009. "Misallocation and Manufacturing TFP in China and India." Quarterly Journal of Economics 124 (4): 1403-48.

Jaimovich, D. 2011. "Macrostructure and Microstructure: Evidence from Overlapping Village Networks in the Gambia.” MPRA Paper No. 38932, Munich Personal RePEc Archive, Munich.

- 2015. "Missing Links, Missing Markets: Evidence of the Transformation Process in the Economic Networks of Gambian Villages.” World Development 66: 645-64.

Kargbo, A. 1983. "An Economic Analysis of Rice Production Systems and Production Organization of Rice Farmers in the Gambia." PhD thesis. Department of Agricultural Economics, Michigan State University.

La Ferrara, E. 2003. "Kin Groups and Reciprocity: A Model of Credit Transactions in Ghana." American Economic Review 93 (5): 1730-51.

Macours, K., A. de Janvry, and E. Sadoulet. 2010. "Insecurity of Property Rights and Social Matching in the Tenancy Market.” European Economic Review 54 (7): 880-99.

Mazzocco, M., and S. Saini. 2012. "Testing Efficiency Risk Sharing with Heterogeneous Risk Preferences.” American Economic Review 102 (1): 428-68.

Midrigan, V., and D. Y. Xu. 2014. "Finance and Misallocation: Evidence from Plant-Level Data." American Economic Review 104 (2): 422-58.

Otsuka, K. 2007. "Efficiency and Equity Effects of Land Markets.” In Handbook of Agricultural Economics vol. 3, edited by R. Evenson and P. Pingali, 2671-703. Netherlands: Elsevier Science.

Pender, J., and M. Fafchamps. 2005. "Land Lease Markets and Agricultural Effciency in Ethiopa.” Journal of African Economies 15 (2): 251-84.

Platteau, J.-P. 1992. "Land Reform and Structural Adjustment in Sub-Saharan Africa: Controversies and Guidelines." FAO Economic and Social Development Paper No. 107, Food and Agriculture Organization of the United Nations, Rome.

Platteau, J.-P., Y. Hayami, and P. Dasgupta. 1998. "Resource Endowments and Agricultural Development: Africa versus Asia." In The Institutional Foundations of East Asian Economic Development, edited by Y. Hayami and M. Aoki, 357-412. New York: Palgrave Macmillan.

Rauch, J. E. 2001. "Business and Social Networks in International Trade." Journal of Economic Literature 39 (4): 1177-203.

Rauch, J. E., and A. Casella. 2003. "Overcoming Informational Barriers to International Resource Allocation: Prices and Ties." Economic Journal 113 (484): 21-42.

Ravallion, M. 1986. “Testing Market Integration.” American Journal of Agricultural Economics 68 (1): 102-9.

Riach, P. A., and J. Rich. 2002. "Field Experiments of Discrimination in the Market Place." Economic Journal 112 (483): F480-F518.

Sadoulet, E., A. de Janvry, and S. Fukui. 1997. "The Meaning of Kinship in Sharecropping Contracts.” American Journal of Agricultural Economics 79 (2): 394-407.

Swindell, K. 1987. "Family Farms and Migrant Labour: The Strange Farmers of the Gambia." Canadian Journal of African Studies 12 (1): 3-17.

Temperley, H. N. 1981. Graph Theory and Applications. Chichester, UK: Ellis Horwood Limited.

Topa, G. 2001. "Social Interactions, Local Spillovers and Unemployment." Review of Economic Studies 68 (2): 26195.

Townsend, R. M. 1994. "Risk and Insurance in Village India.” Econometrica 62 (3): 539-91.

von Braun, J., and P. J. R. Webb. 1989. "The Impact of New Crop Technology on the Agricultural Division of Labor in a West African Setting." Economic Development and Cultural Change 37 (3): 513-34.

Webb, P. 1989. "Intrahousehold Decisionmaking and Resource Control: The Effects of Rice Commercialization in West Africa.” Technical Report, International Food Policy Research Institute. 